\title{
Health of children born to medical radiographers
}

\author{
Eve Roman, Pat Doyle, Pat Ansell, Diana Bull, Valerie Beral
}

\begin{abstract}
Objectives-To develop a reliable method for collecting information on reproductive outcome in an occupational setting; and to investigate the health of children born to medical radiographers.
\end{abstract}

Methods-The study population comprised 6730 members of the College of Radiographers who were, at the time of survey; aged between 30 and 64 years, on the current membership file of the College, and were resident in Britain.

Results-The postal method developed proved to be reliable, with around $87 \%$ of questionnaires being returned. The observed frequencies of reproductive events were broadly in line with findings from other studies: of the 9208 pregnancies reported, $83 \%$ were livebirths, $12 \%$ were miscarriages (gestational age $<20$ weeks), $1 \%$ were stillbirths (gestational age $\geqslant 20$ weeks), and $1 \%$ were other rarer spontaneous adverse events (ectopic pregnancy, blighted ovum, and hydatidiform mole). There was little difference between men and women in the frequency of adverse reproductive events reported, with the exception that male radiographers reported fewer medical terminations, the proportions being $3 \cdot 1 \%$ and $1.4 \%$ for women and men respectively. Among children, the overall risks of major congenital malformation (RR 1.0, 95\%CI 0.9-1.2), chromosomal anomaly (RR 1.4, 95\%CI $0 \cdot 8-2 \cdot 3$ ), and cancer (RR $1 \cdot 2$ 95\%CI $0 \cdot 7-2 \cdot 0)$ were as expected based on general population rates. Borderline excesses of chromosomal anomalies other than Down's syndrome in the children of female radiographers ( $R R$ 3.9, 95\% CI 1.3-9.0, based on five observations), and cancer in the children of male radiographers ( $R R$ $2 \cdot 7,95 \%$ CI $0 \cdot 9-6 \cdot 5$, based on five observations) were noted. The numbers on which these risks are based are small and the findings should be interpreted cautiously. Conclusions-The postal methods developed for obtaining information about reproductive events and child health proved to be reliable in men, as well as in women. Overall, the findings for medical radiographers are reassuring. Doseresponse relations could not, however, be examined as long term dose records of radiographers are not routinely kept in an accessible form.

(Occup Environ Med 1996;53:73-79)
Keywords: ionising radiation; radiographers; pregnancy outcome

The idea that work exposure of parents to potentially hazardous agents may affect the health of their unborn children continues to be a topic of public concern and scientific interest. Although there is much speculation about such prenatal effects, relatively few investigations have been carried out in groups who may have been occupationally exposed to specific substances before and during pregnancy.

Particular controversy surrounds the possible role of low level ionising radiation. The suggestion of Stewart and colleagues, made in 1958, that in utero exposure to diagnostic $x$ rays might increase the risk of childhood leukaemia and other cancers, has taken several decades to settle. ${ }^{1}$ It is now widely accepted that fetuses and young children are more susceptible to the effects of ionising radiation than are adults, and modern concern revolves mainly around the relative importance of the dose of radiation received and age at time of exposure..$^{2-5}$ More controversial today, is the hypothesis that parental preconceptual exposure to low level doses of ionising radiation may be associated with increased risks of cancer and certain chromosomal defects. ${ }^{6-23}$

We describe here the findings from an investigation into the health of children of medical radiographers. The study was set up with two main objectives in mind: firstly to develop a reliable method for collecting data on reproductive outcome and child health; and secondly to determine whether radiographers, children were at increased risk of chromosomal anomalies or cancer.

\section{Subjects and methods}

The study population comprised all members of the College of Radiographers who, at the time of the survey, were on the College's current membership files, aged between 30 and 64 years, and resident in Britain. People under 30 years were not approached because they would have had few pregnancies, and those past retirement because of the difficulty associated with recalling events that occurred several years in the past. Computer generated home or work address labels were provided by the College for each of the 6730 radiographers who fulfilled these criteria. These labels were produced in seven batches over the two year period June 1988 to July 1990: 
radiographers who qualified in earlier years being in the first batch and those qualifying in later years being in the last.

Information about current and past jobs, reproductive history, and offspring's health were collected in two postal stages. In the first stage a questionnaire was sent to all of the 6730 eligible radiographers: packages containing introductory letters from the investigators and the College of Radiographers, the questionnaire, and a prepaid stamped addressed envelope were posted in batches of around 500 over the two year period November 1988 to November 1990. The return of a blank form was requested should the recipient not wish to participate in the study. A further questionnaire and a reminder letter were sent if a reply was not received within eight weeks of the initial posting.

To obtain detailed information about specific adverse health events and occupational history, and to request permission to access relevant medical and occupational records, a second questionnaire was sent to all radiographers who reported children with major congenital malformations, cancer, or serious developmental retardation; and to people whose children had died or who had had a spontaneous fetal loss at 20 weeks gestational age or more. With the aim of permitting further investigation of any anomalous risks which may have been uncovered by the survey, a control sample of radiographers whose children were reported to be unaffected were also sent a second questionnaire: two controls per case being selected from among radiographers in the same stage one batch as their corresponding case. Controls were individually matched to cases by sex and date of birth (to within two years for women and five years for men); and on the child's sex (if liveborn), date of birth (to within two years), and pregnancy order $(1,2$, or $3+)$.

The routines for entry of data from the first questionnaire and case-control matching were specially written for the project in Dbase IV. ${ }^{24}$ The data from the first stage of the study, which formed the basis for selecting cases and controls for the second stage, were coded and entered on to a dedicated microcomputer within three weeks of their receipt. The second stage matching programme had two main components. In the first part, for each case, all potential controls which satisfied the matching criteria were identified, and in the second part two controls per case were assigned. The control assignment routine was specifically

Table 1 Response of radiographers to first questionnaire

\begin{tabular}{lccc}
\hline Questionnaires & $\begin{array}{l}\text { Women } \\
n(\%)\end{array}$ & $\begin{array}{l}\text { Men } \\
n(\%)\end{array}$ & $\begin{array}{l}\text { Total } \\
n(\%)\end{array}$ \\
\hline Total posted & $5838(100)$ & $892(100)$ & $6730(100)$ \\
Returned undelivered & $215(3 \cdot 7)$ & $42(4 \cdot 7)$ & $257(3 \cdot 8)$ \\
Total delivered & $5623(100)$ & $850(100)$ & $6473(100)$ \\
Returned: & & & \\
$\quad$ Completed & $4847(86 \cdot 2)$ & $662(77 \cdot 9)$ & $5509(85 \cdot 1)$ \\
$\quad$ Blankt & $94(1 \cdot 7)$ & $18(2 \cdot 1)$ & $112(1 \cdot 7)$ \\
Not returned & $682(12 \cdot 1)$ & $170(20 \cdot 0)$ & $852(13 \cdot 2)$ \\
\hline
\end{tabular}

^By post office or by current occupants of the household; †a blank questionnaire was requested if the recipient did not wish to participate. designed to achieve the best possible agreement of cases and controls across the data as a whole: cases with only one or two potential controls taking priority over those with several, and the closest match in terms of the parent's date of birth being selected where several choices were possible. For ethical reasons a few people who reported serious adverse events, such as accidental child death, were not included as cases and were excluded from the pool of potential controls.

Various checks were carried out on the information reported in the first and second stages of the survey. As well as routinely checking for consistency between different variables within each stage, the data collected in the two stages were systematically checked for consistency and repeatability against each other. Also, all reports of cancer in offspring were validated against information held in national registration schemes or in medical records. The fact that the study population comprised radiographers familiar with medical terminology undoubtedly contributed to the high quality of data obtained, and no attempt was made to validate reports of adverse pregnancy outcome or congenital malformation.

Standard coding and statistical methods have been used in the analyses. Health problems reported in the survey were coded with the ninth revision of the international classification of diseases (ICD-9), ${ }^{25}$ and significance and $95 \%$ confidence intervals (95\% CIs) were calculated with tables generated from the Poisson distribution. ${ }^{26}$ For cancers, expected numbers were calculated with a person-years method by applying age, sex, and period specific national cancer registration rates for England and Wales to the population of children at risk. ${ }^{27}$ For congenital malformations national data are known to be incomplete, especially for diagnoses made after the first week of life. Maternal age adjusted expected numbers were, therefore, calculated from data derived from the Liverpool Congenital Malformation Registry which, until the early 1990s, collected data from many different sources on malformations diagnosed at any age in the Liverpool region (see methods in ${ }^{28}$ ). These data are known to be of high quality, ${ }^{29}$ and have been used to calculate expected numbers in other studies..$^{30}$ Minor malformations are excluded from the analysis presented here because comparison data were not available (the Liverpool registry does not collect information on skin tags or undescended testis, etc, see table 4 footnotes). Certain other malformations were also excluded because of uncertainty about the severity of diagnosis: congenital dislocation of the hip and talipes, for example, can vary in severity from minor to severe, and the validity of comparing rates is questionable.

\section{Results}

Table 1 summarises by sex the response of the 6730 radiographers who were sent a first stage questionnaire. Two hundred and fifteen $(3 \cdot 7 \%)$ of the questionnaires sent to women 
Table 2 Characteristics and pregnancies reported by radiographers returning a completed first questionnaire

\begin{tabular}{|c|c|c|c|}
\hline & $\begin{array}{l}\text { Women } \\
(n=4847) \\
n(\%)\end{array}$ & $\begin{array}{l}\text { Men } \\
(n=662) \\
n(\%)\end{array}$ & $\begin{array}{l}\text { Total } \\
(n=5509) \\
n(\%)\end{array}$ \\
\hline \multicolumn{4}{|l|}{ Employment at survey: } \\
\hline Radiographer (total) & $4120(85 \cdot 0)$ & $572(86 \cdot 4)$ & $4692(85 \cdot 2)$ \\
\hline Full time & $2528(52 \cdot 1)$ & $548(82 \cdot 8)$ & $3076(55 \cdot 8)$ \\
\hline Part time & $1556(32 \cdot 1)$ & $18(2 \cdot 7)$ & $1574(28 \cdot 6)$ \\
\hline Hours not specified & $36(0 \cdot 7)$ & $6(0.9)$ & $42(0 \cdot 8)$ \\
\hline Not radiographer & $727(15 \cdot 0)$ & $90(13 \cdot 6)$ & $817(14 \cdot 8)$ \\
\hline \multicolumn{4}{|l|}{ Age (y): } \\
\hline$\leqslant 34$ & $990(20 \cdot 4)$ & $160(24 \cdot 2)$ & $1150(20 \cdot 9)$ \\
\hline $35-39$ & $1308(27 \cdot 0)$ & $171(25 \cdot 8)$ & $1479(26 \cdot 8)$ \\
\hline $40-49$ & $1827(37 \cdot 7)$ & $201(30 \cdot 4)$ & $2028(36 \cdot 8)$ \\
\hline$\geqslant 50$ & $702(14 \cdot 5)$ & $128(19 \cdot 3)$ & $830(15 \cdot 1)$ \\
\hline Not reported & $20(0 \cdot 4)$ & $2(0 \cdot 3)$ & $22(0.4)$ \\
\hline \multicolumn{4}{|l|}{ Pregnancy outcomes: } \\
\hline At least one pregnancy & $3397(70 \cdot 1)$ & $485(73 \cdot 3)$ & $3882(70 \cdot 5)$ \\
\hline \multicolumn{4}{|l|}{ Livebirths } \\
\hline 0 & $1599(33.0)$ & $186(28 \cdot 1)$ & $1785(32 \cdot 4)$ \\
\hline 1 & $739(15 \cdot 2)$ & $103(15 \cdot 6)$ & $842(15 \cdot 2)$ \\
\hline 2 & $1834(37.9)$ & $263(39 \cdot 7)$ & $2097(38 \cdot 1)$ \\
\hline $3+$ & $675(13.9)$ & $110(16 \cdot 6)$ & $785(14 \cdot 2)$ \\
\hline \multirow{2}{*}{\multicolumn{4}{|c|}{ Fetal death (miscarriages }} \\
\hline & & & \\
\hline 0 & $3792(78 \cdot 2)$ & $535(80 \cdot 8)$ & $4327(78 \cdot 5)$ \\
\hline 1 & $768(15 \cdot 8)$ & $92(13.9)$ & $860(15 \cdot 6)$ \\
\hline 2 & $208(4 \cdot 3)$ & $25(3 \cdot 8)$ & $233(4 \cdot 2)$ \\
\hline $3+$ & $79(1 \cdot 6)$ & $10(1 \cdot 5)$ & $89(1 \cdot 6)$ \\
\hline \multicolumn{4}{|l|}{ Infertility: } \\
\hline Treatment for infertility & $287(5.9)$ & $46(7 \cdot 0)$ & $333(6 \cdot 0)$ \\
\hline Primary infertility & $146(3 \cdot 0)$ & $20(3 \cdot 0)$ & $166(3.0)$ \\
\hline
\end{tabular}

^Respondent or partner reporting one or more pregnancies (any outcome); tconsulted a doctor about infertility and received treatment; $\neq$ treated for infertility and never pregnant.

Table 3 Pregnancies and their outcomes reported by radiographers in the first questionnaire

\begin{tabular}{lccc}
\hline & $\begin{array}{l}\text { Women } \\
n(\%)\end{array}$ & $\begin{array}{l}\text { Men } \\
n(\%)\end{array}$ & $\begin{array}{l}\text { Total } \\
n(\%)\end{array}$ \\
\hline Total pregnancies & $8038(100)$ & $1170(100)$ & $9208(100)$ \\
Livebirths: & $6609(82 \cdot 2)$ & $998(85 \cdot 3)$ & $7607(82 \cdot 6)$ \\
$\quad$ Birth weight $(\mathrm{g})^{\star}:$ & $344(5 \cdot 2)$ & $56(5 \cdot 6)$ & $400(5 \cdot 3)$ \\
$\quad \leqslant 2500$ & $923(14 \cdot 0)$ & $159(15 \cdot 9)$ & $1082(14 \cdot 2)$ \\
-3000 & $2498(37 \cdot 8)$ & $361(36 \cdot 2)$ & $2859(37 \cdot 6)$ \\
-3500 & $2779(42 \cdot 0)$ & $370(37 \cdot 1)$ & $3149(41 \cdot 4)$ \\
$\quad 3500$ & $65(1 \cdot 0)$ & $52(5 \cdot 2)$ & $117(1 \cdot 5)$ \\
$\quad$ not reported & $1016(12 \cdot 6)$ & $126(10 \cdot 8)$ & $1142(12 \cdot 4)$ \\
Fetal deathst: & $84(1 \cdot 0)$ & $18(1 \cdot 5)$ & $102(1 \cdot 1)$ \\
$\quad<20$ weeks & $1100(13 \cdot 7)$ & $144(12 \cdot 3)$ & $1244(13 \cdot 5)$ \\
$\geqslant 20$ weeks & $52(0 \cdot 7)$ & $9(0 \cdot 8)$ & $61(0 \cdot 7)$ \\
Total & $21(0 \cdot 3)$ & $2(0 \cdot 2)$ & $23(0 \cdot 2)$ \\
Ectopic pregnancy & $4(0 \cdot 1)$ & $1(0 \cdot 1)$ & $5(0 \cdot 1)$ \\
Blighted ovum & $252(3 \cdot 1)$ & $16(1 \cdot 4)$ & $268(2 \cdot 9)$ \\
Hydatidiform mole & Medical termination & &
\end{tabular}

^Percentage expressed as a proportion of all livebirths; texcludes 28 deaths in twin pregnancies.

and $42(4 \cdot 7 \%)$ of the questionnaires sent to men were returned undelivered, either by the post office or by the current occupants of the address. The overall return among the remaining 6473 radiographers was good, with $5621(86.9 \%)$ of questionnaires being accounted for. The proportion of completed questionnaires returned was higher among women than men, being around $86 \%$ and $78 \%$ respectively.

Table 2 shows the characteristics of the 4847 women and 662 men who returned a completed questionnaire in the first stage of the study. Around $85 \%$ of women and $86 \%$ of men were employed as radiographers when the survey was carried out. As might be expected, a much larger proportion of women than men were employed in a part time capacity $(32.1 \% v$ $2 \cdot 7 \%$ ). The age distributions of female and male respondents were also slightly different, there being proportionately more men than women in the youngest and oldest age groups.

Overall, $3397(70 \cdot 1 \%)$ women reported having had at least one pregnancy and 485
$(73.3 \%)$ men reported one or more pregnancies in their partner (table 2). Nearly all of those (96\%) reporting one or more pregnancies had had at least one liveborn child. The expected preference for two children is clearly seen within the data, with $38.1 \%$ of the total, and $54.0 \%$ of those who reported one or more pregnancies, having had two livebirths. Almost a quarter of respondents said that they or their partner had had at least one miscarriage or stillbirth; with 89 (1.6\%) giving details of three or more such adverse advents. Of the 333 radiographers $(6 \%)$ who consulted a doctor and received treatment for a fertility problem, 166 $(3 \%)$ said that they had not succeeded in starting a pregnancy; this $3 \%$ was similar for men and women.

Table 3 shows more detailed information about the 9208 individual pregnancies reported in the survey. The proportions of the different pregnancy outcomes are broadly in line with findings from other studies: $83 \%$ were livebirths, $12 \%$ were miscarriages (gestational age $<20$ weeks), $1 \%$ were late fetal deaths or stillbirths (gestational age $\geqslant 20$ weeks), and $1 \%$ were other rarer spontaneous adverse events (ectopic pregnancy, blighted ovum, and hydatidiform mole). The birth weight distribution of livebirths is also in line with expectation, with just over $5 \%$ of babies being of low birth weight $(\leqslant 2500 \mathrm{~g})$. All in all, there is little difference between the reports of mothers and fathers, with the possible exception that male radiographers seem to be comparatively less certain of their children's birth weights (the proportions of babies whose birth weights were not reported being $1.0 \%$ and $5 \cdot 2 \%$ for mothers and fathers respectively) and of their partners, medical terminations (the proportions reported being $3 \cdot 1 \%$ for women and $1.4 \%$ for men).

Table 4 compares the numbers of major congenital malformations reported in the offspring of radiographers with those expected on the basis of data complied by the Liverpool Congenital Malformation Registry. Overall, there is no evidence of an excess or deficit in reported major malformations among the children and pregnancies of male and female radiographers combined (RR 1.0, 95\%CI 0.9-1.2); and in particular, no excess of Down's syndrome is evident (RR $1 \cdot 0,95 \% \mathrm{CI}$ 0.5-1.9). Within specific systems, however, two significantly high risks were found, both of which were largely due to the higher than expected number of adverse outcomes reported by female radiographers: the first being within the "other musculoskeletal" category and the second being within the "chromosomal anomalies other than Down's syndrome" group. The excess of malformations within the other musculoskeletal category (RR $2 \cdot 1,95 \% \mathrm{CI} 1 \cdot 4-3 \cdot 1$ ), is difficult to interpret because of the heterogeneity of disorders included within this system group. Examination of the individual diagnoses showed that the excess was primarily due to the subcategory "anomalies of the thorax and neck": the specific malformations within this subgroup reported by female radiographers 
Table 4 Congenital malformations observed (Obs), expected (Exp), and the Obs/Exp ratio (95\% CI), in liveborn children, stillbirths, * and medical terminations ${ }^{\star}$ of radiographers, by malformation system $f$ and parental sex

\begin{tabular}{|c|c|c|c|c|c|c|c|c|c|}
\hline \multirow{2}{*}{$\begin{array}{l}\text { Malformation by } \\
\text { systemt (ICD-9) }\end{array}$} & \multicolumn{3}{|c|}{ Women } & \multicolumn{3}{|l|}{ Men } & \multicolumn{3}{|c|}{ Total } \\
\hline & Obs & $\operatorname{Exp} \neq$ & Ratio $(95 \%$ CI) & Obs & Expt & Ratio $(95 \%$ CI) & Obs & $\operatorname{Exp} \ddagger$ & Ratio $(95 \%$ CI) \\
\hline Total & 140 & $143 \cdot 8$ & $1 \cdot 0(0 \cdot 8-1 \cdot 2)$ & 23 & $22 \cdot 7$ & $1.0(0.6-1.5)$ & 163 & $165 \cdot 7$ & $1 \cdot 0(0 \cdot 9-1 \cdot 2)$ \\
\hline $\begin{array}{l}\text { Central nervous } \\
\text { system }(740 \cdot 0-742.9)\end{array}$ & 17 & $17 \cdot 7$ & $1.0(0.6-1.5)$ & 3 & $3 \cdot 5$ & $0.9(0.2-2.5)$ & 20 & $21 \cdot 2$ & $0.9(0.6-1.5)$ \\
\hline Eye and ear $(743 \cdot 0-744 \cdot 2)$ & 9 & $6 \cdot 6$ & $1.4(0 \cdot 6-2 \cdot 6)$ & 2 & $1 \cdot 2$ & $1 \cdot 7(0 \cdot 2-6 \cdot 0)$ & 11 & $7 \cdot 8$ & $1 \cdot 4(0 \cdot 7-2 \cdot 5)$ \\
\hline $\begin{array}{l}\text { Alimentary system } \\
\quad(749 \cdot 0-749 \cdot 2,750 \cdot 3-751 \cdot 9 \\
\text { excluding } 750 \cdot 6)\end{array}$ & 12 & $17 \cdot 1$ & $0.7(0.4-1 \cdot 2)$ & 3 & $2 \cdot 6$ & $1 \cdot 2(0 \cdot 2-3 \cdot 4)$ & 15 & $19 \cdot 7$ & $0.8(0.4-1.3)$ \\
\hline Cardiovascular system $(745 \cdot 0-747.9)$ & 40 & 54.9 & $0.7(0.5-1 \cdot 0)$ & 4 & $8 \cdot 4$ & $0.5(0 \cdot 1-1 \cdot 2)$ & 44 & $62 \cdot 5$ & $0.7(0.5-1.0)$ \\
\hline $\begin{array}{l}\text { Urogenital system }(752 \cdot 0-753.9 \\
\text { excluding } 752 \cdot 5)\end{array}$ & 20 & $16 \cdot 8$ & $1 \cdot 2(0 \cdot 7-1 \cdot 8)$ & 3 & $2 \cdot 5$ & $1 \cdot 2(0 \cdot 3-3 \cdot 5)$ & 23 & $19 \cdot 2$ & $1 \cdot 2(0.8-1 \cdot 8)$ \\
\hline Limbs $(754 \cdot 4,755 \cdot 0-755 \cdot 9)$ & 8 & $11 \cdot 6$ & $0.7(0.3-1 \cdot 4)$ & 2 & 0.9 & $2 \cdot 2(0 \cdot 3-8 \cdot 0)$ & 10 & $12 \cdot 6$ & $0.8(0.4-1 \cdot 5)$ \\
\hline $\begin{array}{l}\text { Other musculoskeletal }(750 \cdot 6,744 \cdot 5-744 \cdot 9 \text {, } \\
748 \cdot 0-748 \cdot 1,754 \cdot 0-754 \cdot 2,754 \cdot 8 \text {, } \\
756 \cdot 0-756 \cdot 9)\end{array}$ & 23 & $10 \cdot 3$ & $2 \cdot 2(1.4-3 \cdot 4)$ & 2 & $1 \cdot 6$ & $1 \cdot 3(0 \cdot 2-4 \cdot 5)$ & 25 & 11.9 & $2 \cdot 1(1 \cdot 4-3 \cdot 1)$ \\
\hline Chromosomal (758.0-758.9): & 11 & $8 \cdot 8$ & $1 \cdot 3(0 \cdot 6-2 \cdot 3)$ & 4 & $2 \cdot 0$ & $2 \cdot 0(0 \cdot 6-5 \cdot 1)$ & 15 & $10 \cdot 8$ & $1 \cdot 4(0 \cdot 8-2 \cdot 3)$ \\
\hline Down's syndrome $(758.0)$ & 6 & $7 \cdot 4$ & $0.8(0 \cdot 3-1 \cdot 8)$ & 3 & $1 \cdot 6$ & $1.9(0.4-5.5)$ & 9 & $9 \cdot 1$ & $1.0(0.5-1.9)$ \\
\hline $\begin{array}{l}\text { Other chromosomal } \\
\text { anomalies }(758 \cdot 1-758 \cdot 9)\end{array}$ & 5 & $1 \cdot 3$ & $3.9(1.3-9 \cdot 0)$ & 1 & $0 \cdot 4$ & $2 \cdot 5(0 \cdot 1-13 \cdot 9)$ & 6 & $1 \cdot 7$ & $3 \cdot 5(1 \cdot 3-7 \cdot 7)$ \\
\hline
\end{tabular}

*Stillbirths defined as fetal deaths at 20 weeks gestational age or more. Medical terminations were those undertaken because of detected abnormality in fetus. †Malformations by system classified according to the ICD-9 groupings. Observed and expected numbers do not include the following diagnoses: pyloric stenosis; unspecified heart murmur; patent ductus arteriosis in babies $<28$ weeks gestation or weighing < $1000 \mathrm{~g}$, or both; undescended testis; hydrocele; hypospadias with urinary meatus in front of coronary sulcus; inguinal hernias; congenital dislocation of hips; "unstable" hips; talipes; lesions on skin; ear tags; tongue tie; branchial cleft; preauricular sinus; unspecified anomalies of ears and nose.

$\ddagger$ Expected numbers calculated from maternal age specific rates derived from the Liverpool Congenital Malformations Registry. This register includes malformations in stillbirths, medical terminations, and livebirths diagnosed at any age after birth.

Table 5 Malignancies observed (Obs), expected (Exp), and the Obs/Exp ratio (95\% CI) reported ${ }^{\star}$ in the children of radiographers by malignancy, child's age at diagnosis, and parental sex

\begin{tabular}{|c|c|c|c|c|c|c|c|c|c|}
\hline \multirow[b]{2}{*}{ Malignancy (ICD-9) } & \multicolumn{3}{|c|}{ Women } & \multicolumn{3}{|l|}{ Men } & \multicolumn{3}{|c|}{ Total } \\
\hline & Obs & Expt & Ratio (95\% CI) & Obs & Expt & Ratio $(95 \%$ CI) & $O b s$ & Expt & Ratio $(95 \%$ CI) \\
\hline $\begin{array}{l}\text { All malignancies (140-208): } \\
\text { Age (y): }\end{array}$ & 11 & $11 \cdot 2$ & $1.0(0.5-1.8)$ & 5 & $1 \cdot 8$ & $2.7(0.9-6.5)$ & 16 & $13 \cdot 0$ & $1 \cdot 2(0 \cdot 7-2 \cdot 0)$ \\
\hline $0-4$ & 4 & $4 \cdot 2$ & $1 \cdot 0(0 \cdot 3-2 \cdot 4)$ & 1 & $0 \cdot 6$ & $1.7(0.0-9 \cdot 3)$ & 5 & $4 \cdot 8$ & $1.0(0.4-2.4)$ \\
\hline 5-9 & 1 & $2 \cdot 0$ & $0.5(0.0-2 \cdot 8)$ & 1 & $0 \cdot 3$ & $3.3(0 \cdot 1-18.9)$ & 2 & $2 \cdot 3$ & $0.9(0 \cdot 1-3 \cdot 1)$ \\
\hline $10-14$ & 2 & 1.5 & $1 \cdot 3(0 \cdot 2-4 \cdot 8)$ & 1 & $0 \cdot 2$ & $5 \cdot 0(0 \cdot 1-27 \cdot 9)$ & 3 & $1 \cdot 7$ & $1.8(0.4-5 \cdot 2)$ \\
\hline$\geqslant 15$ & 4 & 3.5 & $1 \cdot 1(0 \cdot 5-1 \cdot 8)$ & 2 & $0 \cdot 7$ & $2.9(0.2-10 \cdot 3)$ & 6 & $4 \cdot 2$ & $1.4(0 \cdot 5-3 \cdot 1)$ \\
\hline Leukaemia and non-Hodgkin's & & & & & & & & & \\
\hline $\begin{array}{l}\text { lymphoma }(200,202,204-208) \text { : } \\
\text { Age (y): }\end{array}$ & 5 & $3 \cdot 8$ & $1 \cdot 3(0 \cdot 4-3 \cdot 1)$ & 2 & $0 \cdot 6$ & $3 \cdot 3(0 \cdot 4-12 \cdot 0)$ & 7 & $4 \cdot 4$ & $1 \cdot 6(0 \cdot 6-3 \cdot 3)$ \\
\hline $0-4$ & 3 & $1 \cdot 8$ & $1 \cdot 7(0.3-4 \cdot 9)$ & 0 & $0 \cdot 3$ & $0.0(0.0-12.3)$ & 3 & $2 \cdot 1$ & $1.4(0.3-4.2)$ \\
\hline $5-9$ & 1 & 0.9 & $1 \cdot 1(0 \cdot 0-6 \cdot 2)$ & 1 & $0 \cdot 1$ & $10.0(0.3-55.9)$ & 2 & $1 \cdot 0$ & $2 \cdot 0(0 \cdot 2-7 \cdot 2)$ \\
\hline $10-14$ & 1 & $0 \cdot 5$ & $2 \cdot 0(0 \cdot 1-11 \cdot 1)$ & 0 & $0 \cdot 1$ & $0.0(0.0-36.9)$ & 1 & $0 \cdot 6$ & $1 \cdot 7(0 \cdot 0-9 \cdot 3)$ \\
\hline$\geqslant 15$ & 0 & $0 \cdot 6$ & $0.0(0.0-6 \cdot 2)$ & 1 & $0 \cdot 1$ & $10 \cdot 0(0 \cdot 3-55 \cdot 7)$ & 1 & $0 \cdot 7$ & $1.4(0 \cdot 0-8 \cdot 0)$ \\
\hline $\begin{array}{l}\text { All except leukaemia and non- } \\
\text { Hodgkin's lymphoma }(140-199,201) \text { : }\end{array}$ & 6 & $7 \cdot 4$ & $0.8(0 \cdot 3-1 \cdot 8)$ & 3 & $1 \cdot 2$ & $2 \cdot 5(0 \cdot 5-7 \cdot 3)$ & 9 & $8 \cdot 6$ & $1 \cdot 1(0 \cdot 5-2 \cdot 0)$ \\
\hline $\begin{array}{c}\text { Age }(y): \\
0-4\end{array}$ & 1 & $2 \cdot 4$ & $0.4(0.0-2.3)$ & 1 & $0 \cdot 3$ & $3 \cdot 3(0 \cdot 1-18 \cdot 6)$ & 2 & $2 \cdot 7$ & $0 \cdot 7(0 \cdot 1-2 \cdot 7)$ \\
\hline $5-9$ & 0 & $1 \cdot 1$ & $0 \cdot 0(0 \cdot 0-3 \cdot 4)$ & 0 & $0 \cdot 2$ & $0.0(0.0-18.5)$ & 0 & $1 \cdot 3$ & $0.0(0.0-2 \cdot 8)$ \\
\hline $10-14$ & 1 & $1 \cdot 0$ & $1.0(0.0-5 \cdot 6)$ & 1 & $0 \cdot 1$ & $10.0(0.3-55 \cdot 7)$ & 2 & $1 \cdot 1$ & $1.8(0 \cdot 2-6 \cdot 6)$ \\
\hline$\geqslant 15$ & 4 & $2 \cdot 9$ & $1 \cdot 4(0 \cdot 4-3 \cdot 5)$ & 1 & $0 \cdot 6$ & $1.7(0.0-9 \cdot 3)$ & 5 & $3 \cdot 5$ & $1.4(0.5-3.3)$ \\
\hline
\end{tabular}

^All reports were validated against national cancer registration data or medical records. $†$ Expected numbers calculated from age, sex, and period specific incidences for England and Wales $(1971-86)$.

being congenital torticollis (three cases), sternomastoid tumour (two cases), spina bifida occulta/sinus (three cases) and bifid rib (one case). These diagnoses are likely to be under reported in the comparative data as they are not easily detected and can often be missed in a routine setting. The excess of chromosomal anomalies other than Down's syndrome is equally difficult to interpret: the relative risks for women, men, and both sexes combined being 3.9 (95\%CI $1.3-9.0), \quad 2.5(95 \% \mathrm{CI}$ $0 \cdot 1-13 \cdot 9)$, and $3 \cdot 5(95 \% \mathrm{CI} 1 \cdot 3-7 \cdot 7)$ respectively. Diagnoses included in this category reported by female radiographers were four cases of Turner's syndrome (two of which were diagnosed before birth and the pregnancies terminated) and one case of gross chromosomal anomaly in a pregnancy which was terminated before birth. The single other chromosomal anomaly reported by a male radiographer was a trisomy in chromosome 17 in a pregnancy which was also terminated.

Table 5 compares the numbers of cancers reported in the children of radiographers with those expected on the basis of national rates. Although the numbers are small, data are presented in five year age groups and for two main diagnostic categories. Overall, there is little evidence to suggest that the children of radiographers are at any increased risk of cancer: 16 malignancies were reported whereas 13.0 were expected (RR $1 \cdot 2,95 \%$ CI $0 \cdot 7-2 \cdot 0)$. Among women's children the numbers observed and expected are almost identical, being 11 and 11.2 respectively. Amongst men's children, however, there is a marginal, although non-significant, excess: five malignancies being observed whereas 1.8 were expected (RR $2 \cdot 7,95 \%$ CI $0 \cdot 9-6 \cdot 5)$. Table 6 shows more information about the 16 malig- 
Table 6 Malignancies diagnosed in the children of radiographers by age at diagnosis and $I C D^{-9}$

\begin{tabular}{|c|c|c|}
\hline $\begin{array}{l}\text { Age at } \\
\text { diagnosis } \\
\text { (y) }\end{array}$ & Diagnosis (ICD-9) & $\begin{array}{l}\text { Sex of } \\
\text { radiographer }\end{array}$ \\
\hline $0-4$ & $\begin{array}{l}\text { Retinoblastoma }(1905)^{\star} \\
\text { Brain cancer (1919) } \\
\text { Acute lymphoblastic leukaemia }(2040) \\
\text { Acute lymphoblastic leukaemia }(2040) \\
\text { Acute lymphoblastic leukaemia }(2040)\end{array}$ & $\begin{array}{l}\mathrm{M} \\
\mathrm{F} \\
\mathrm{F} \\
\mathrm{F} \\
\mathrm{F}\end{array}$ \\
\hline 5-9 & $\begin{array}{l}\text { Acute lymphoblastic leukaemia (2040) } \\
\text { Reticular sarcoma (2000) }\end{array}$ & $\begin{array}{l}\mathbf{F} \\
\mathbf{M}\end{array}$ \\
\hline $10-14$ & $\begin{array}{l}\text { Glioma (1919) } \\
\text { Hodgkin's disease (2016) } \\
\text { Acute myeloid leukaemia (2050) }\end{array}$ & $\begin{array}{l}\mathbf{M} \\
\mathbf{F} \\
\mathbf{F}\end{array}$ \\
\hline $15-19$ & $\begin{array}{l}\text { Teratoma of testis (1869) } \\
\text { Hodgkin's disease (2016) } \\
\text { Hodgkin's disease (2016) }\end{array}$ & $\begin{array}{l}F \\
F \\
F\end{array}$ \\
\hline $\begin{array}{l}20-24 \\
25-29 \\
30-24\end{array}$ & $\begin{array}{l}\text { Acute myeloid leukaemia (2050) } \\
\text { Breast cancer (1744) } \\
\text { Teratoma of testis (1869) }\end{array}$ & $\begin{array}{l}\mathbf{M} \\
\mathbf{M} \\
\mathbf{F}\end{array}$ \\
\hline
\end{tabular}

^Non-familial, bilateral.

nancies, which comprise a heterogeneous group (to prevent identification of individual people, dates of birth of children and parents are not presented here).

To permit further investigation of any anomalous risks observed, a case-control design was adopted in the second stage of the study (see subjects and methods). The original intent had been to obtain dosimetry and employment records of cases and their corresponding controls, so that dose-response relations could be investigated. However, although radiographers are subject to routine dose assessments, long term dose records have not, generally, been kept (see discussion). Although further information about the work histories of radiographers before the birth of their children was collected in the second stage, a thorough review of these data on chromosomal anomalies other than Down's syndrome (table 4) and malignancies (table 5) showed no notable differences between cases and their corresponding matched controls. All cases and controls had trained and worked in radiography before their children were conceived. Also, cases and their corresponding controls reported almost identical durations and patterns of employment in radiography, and all reported a similar spectrum of radiographic duties and exposures at work (diagnostic radiography and portable set work, for example). Given the close matching of cases and controls for sex, date of birth, and number of previous pregnancies this is, perhaps, not surprising.

\section{Discussion}

The postal method developed for this study proved to be reliable, and the quality of the information provided by the respondents was good. The overall response rate was $\mathbf{8 6 . 8 \%}$ : with $85.1 \%$ of questionnaires being returned completed and $1.7 \%$ blank (refusal). The exact response, expressed as a proportion of questionnaires actually received by the intended respondents is, however, likely to have been greater than this as some of the 852 $(13 \cdot 2 \%)$ unreturned questionnaires were probably not received because the address held by the College was out of date. Moreover, it is possible that part of the difference between the proportions of completed returns for men $(78 \%)$ and women $(86 \%)$ could have been due to the fact that male radiographers addresses were, comparatively, less reliable: either because the men were more mobile or because they were less likely to inform the College of their new address.

The reproductive patterns seen within this group of radiographers seems to be typical of 30 to 64 year olds in the general population ${ }^{31}$ : around $70 \%$ reported at least one pregnancy and nearly $40 \%$ reported two livebirths. The observed frequency of fetal death also agrees well with other surveys of medical personnel ${ }^{32}$ : $12 \%$ of all pregnancies ended in miscarriage and $1 \%$ in stillbirth. Also, the numbers of ectopic pregnancies $(0.7 \%)$, blighted ova $(0 \cdot 2 \%)$, and hydatidiform moles $(0 \cdot 1 \%)$, were in line with expectation. ${ }^{33}{ }^{34}$ Comparable data on infertility are sparse, and it is noteworthy that $3 \%$ of men and $3 \%$ of women supplied information that suggested that they or their partners had primary infertility.

Relatively few published studies have included data on reproductive events reported by men, as well as by women. In this context, the present investigation provides a valuable opportunity to compare the information supplied by men with that supplied by women. In general, both sexes reported similar frequencies of events: $70 \%$ of women and $73 \%$ of men gave details of at least one pregnancy. Also, almost identical proportions of men and women stated that they, or their partner, had a fertility problem. The main difference between the sexes was seen in the recording of children's birth weights and medical terminations. Although women and men reported similar frequencies of low birth weight babies $(5 \cdot 2 \%$ and $5.6 \%$ respectively), only $1.0 \%$ of mothers compared with $5 \cdot 2 \%$ of fathers failed to record their child's weight at birth on the questionnaire. For medical terminations, $3 \cdot 1 \%$ of women and $1.4 \%$ of men gave details about such events.

There is little indication that the offspring of radiographers are at increased risk of chromosomal anomaly (RR $1 \cdot 4,95 \%$ CI $0 \cdot 8-2 \cdot 3$ ) or cancer (RR 1.2, 95\% CI 0.7-2.0). An excess of chromosomal anomalies other than Down's syndrome (RR 3.5, 95\% CI $1 \cdot 3-7 \cdot 7$, based on six observations) and a marginally higher than expected number of cancers in the children of male radiographers (RR $2 \cdot 7,95 \%$ CI $0 \cdot 9-6 \cdot 5$, based on five observations) were noted. The numbers on which these risks are based are small and the findings should be interpreted cautiously. The fact that the observed excess of chromosomal anomalies was not present for Down's syndrome also weakens the suggestion that these data show a real parental occupational effect.

To permit further investigation of any anomalous risks observed, permission to access employment and dosimetry records was requested in the second case-control stage of the study: the intention being to link the data from the second stage of the survey with health physics records. This proved to be 
impossible as radiographers' dosimetry data are not routinely kept: although radiographers are issued with personal dosimeters to monitor their radiation exposures to external sources of ionising radiation their doses are, in general, considered to be insufficient to require them to be designated as classified radiation workers. ${ }^{35}$

In any investigation, such as the one reported here, the possibility of bias needs to be considered. The expected numbers of events for congenital malformations and cancer were derived from general population data. The fact that the overall levels of cancer and congenital malformation in the offspring of medical radiographers were close to expectation suggests that the comparison data were probably appropriate. Nevertheless, it is possible that the findings for chromosomal anomalies other than Down's syndrome and for cancer in the children of male radiographers could be artifactual. Although data from the Liverpool Malformation Registry have been used elsewhere,$^{30}$ it is conceivable that there is underrecording of this particular group of malformations. Moreover, although detailed inspection of the parental reports confirmed the high quality of the information provided, individual diagnoses were not checked against medical records. For cancer, on the other hand, comparison was made with national data and all parental reports were carefully validated against medical records. Neverthelessdespite the similarity between the reports of men and women for other adverse reproductive events - the possibility cannot be entirely ruled out that the differential response rates of men and women to the survey as a whole $(78 \% v 86 \%)$ could have contributed to the findings for cancer.

The present investigation does not include all people who have ever trained and worked in radiography in the United Kingdom, but was restricted to those aged 30-64 years, who were resident in Britain and were on the current membership list of the College of Radiographers between 1988 and 1990. Although nearly all of those surveyed had worked and trained in radiography before their first pregnancy, continuous employment as a radiographer cannot be assumed. Also, the possible effects that having a sick child may have had on whether or not a person continues in radiography and remains on the current membership list could not be assessed in these data. Nevertheless, the study contains a large body of information about the reproductive histories of people who have made their career in radiography. Moreover, other much larger studies of people potentially exposed to ionising radiation at work are currently underway. One such study is linking dosimetry information contained within the National Registry of Radiation Workers (NRRW) with records of childhood cancer held in the National Registry of Childhood Tumours. ${ }^{36}$ Another, the nuclear industry family study (NIFS), using similar methods to the present study, is linking routinely kept health physics data to information on reproductive events and child health supplied by over 60000 current and past employees of the nuclear industry. ${ }^{37}$ This study will be able to link all health outcomes to accurate employment details, including dates and places of work and radiation exposure measurements.

In conclusion, the methods developed for this study proved to be reliable and have already been adapted for use in other investigations. With the exception of medical terminations, male radiographers were as likely as their female counterparts to report adverse outcomes such as fetal death, infertility, low birth weight babies, and congenital malformation and cancer in their children. Overall, the findings are reassuring, with the observed frequencies of most adverse reproductive events being in line with expectation. The possible excesses of chromosomal anomalies other than Down's syndrome in the children of female radiographers, and the borderline excess of cancers in the children of male radiographers are perhaps worthy of further investigation in other workforces potentially exposed to ionising radiation for whom long term dose records are readily available.

We are grateful to the many radiographers who participated in this survey, and to the College of Radiographers for their help and support throughout. Cherill Scott and Claire-Marie Fortin were involved with study design and implementation, and David Cowan developed the computer software. Margo Pelerin, Sheena Dawson, and Barbara Crossley helped enter and check data, and Diane Deciacco assisted with manuscript and check data, and Diane Deciacco assisted with manuscrip preparation. The study was supported by the Health and Safety
Executive, the Medical Research Council, and the Imperial Executive, the Medical
Cancer Research Fund.

1 Stewart AM, Webb JW, Giles BD. A survey of childhood malignancies. BMf 1958;I:1495-508.

2 Graham S, Morton LL, Lilienfeld M, Schuman RG, Dowd JE, Hempelmann L. Preconception, intrauterine and postnatal irradiation as related to leukaemia. National Cancer Institute Monographs 1966;19:347-71.

3 Alberman E, Polani PE, Roberts JAF, Spicer CC, Elliot $M$, Armstrong E. Parental exposure to $x$ irradiation and Down's syndrome. Ann Hum Genet 1972;36:195-208.

4 Alberman E, Polani PE, Roberts JAF, Spicer CC, Elliott M, Armstrong E. Parental $x$ irradiation and chromosome constitution of their spontaneously aborted fetuses. $A n n$ Hum Genet 1972;36:185-94.

5 Bross IDJ, Natarajan N. Risk of leukaemia in susceptible children exposed to preconception, in utero and postnatal radiation. Prev Med 1974;3:361-9.

6 Uchida IA. Maternal radiation and trisomy 21. In: Hook EB, Porter IH, eds. Population cytogenetics: studies in humans. New York: Academic Press, 1977:285-99.

7 Kneale GW, Stewart AM. Pre-conception $x$ rays and childhood cancers. Br f Cancer 1980;41:222-6.

8 Shiona PH, Chung CS, Myrianthopolous NS. Preconception radiation, intrauterine diagnostic radiation conception radiation, intrauterine diagnostic radiation and child $681-6$.

9 Gilman EA, Kneale GW, Knox EG, Stewart AM Pregnancy $x$ rays and childhood cancers: effects of exposure, age and radiation dose. Fournal of Radiological Protection 1988;8:3-8.

10 Bithell JF, Stiller CA. A new calculation of the carcinogeni risk of obstetric $x$ raying. Stat Med 1988;7:857-64.

11 Rose KSB. Pre-1989 epidemiological surveys of low-leve dose pre-conception irradiation. Fournal of Radiological Protection 1990;10:177-84.

12 Shu XO, GaoYT, Brinton LA, Linet MS, Tu JT, Sheng W, t al. A population-based case-control study of childhood leukaemia in Shanghai. Cancer 1988;62:635-44.

13 MacMahon B. Some recent issues in low-exposure radiation epidemiology. Environ Health Perspect 1989;81: 131-5.

14 Bunin GR, Meadows AT, Emanuel BS, Buckley JD, Woods WG, Hammond GD. Pre-and post conception Woods WG, Hammond GD. Pre-and post conception factors associated with sporadic heritable and non-

15 Mole RH. Childhood cancer after prenatal exposure to Mole $\mathrm{RH}$. Childhood cancer after prenatal exposure to
diagnostic $x$ ray examination in Britain. Br $\mathcal{f}$ Cancer diagnostic $x$ ray

16 Committee on the Biological Effects of Ionizing Radiations. Health effects of exposure to low levels of ionizing radiation BEIR V. Washington, DC: National Academy of Sciences, 1990 . 
17 Francis J, Snee M. A case-control study of trisomy 21 and maternal pre-conceptual radiography. Clin Radiol 1991; 43:343-6.

18 Beral V, Roman E, Bobrow M, eds. Childhood cancer and nuclear installations. London: BMJ Publishing Group, 1993

19 Sorahan T, Roberts PJ. Childhood cancer and parental exposure to ionising radiation: preliminary findings from the Oxford survey of childhood cancers. Am ₹ Ind Med 1993;23:343-54

20 Shu XO, Jin F, Linet MS, Zheng W, Clemens J, Mills J, et al. Diagnostic $x$ ray and ultrasound exposure and risk of childhood cancer. Br f Cancer 1994;70:331-6.

21 Doll R, Evans AJ, Darby SC. Paternal exposure not to blame. Nature 1994;367:678-80.

22 Shu XO, Reaman GH, Lampkin B, Sathar HN, Pendergrass TW, Robison LL. Association of paternal diagnostic $x$ ray exposure with risk of infant leukaemia. Cancer Epidemiol Biomarkers Prev 1994;3:645-53.

23 Sorahan T, Lancashire RJ, Temperton DH, Heighway WP. Childhood cancer and paternal exposure to an ionizing radiation: a second report from the Oxford survey of childhood cancers. Am $\mathcal{F}$ Ind Med 1995;28:71-8.

24 Dbase IV. Aston Tate, 1988.

25 World Health Organisation. International classification of diseases, 9th rev, 1975. Geneva: WHO, 1977.

26 Bailer JC, Ederer F. Significance factors for the ratio of a Poisson variable to its expectation. Biometrics 1920: Poisson

27 Coleman M, Douglas A, Herman C, Peto J. Cohort analysis with a FORTRAN computer program. Int $f$ Epidemiol 1986;15:134-7

28 Leck I, Smithells RW. The ascertainment of malformations. Lancet 1963;i:101-3.

29 Dutton SJ, Owens JR, Harris F. Ascertainment of congenital malformations: a comparative study of two systems. F Epidemiol Community Health 1991;45:294-8.

30 Beral V, Doyle P, for the MRC working party on children conceived by in vitro fertilization. Births in Great Britain resulting from assisted conception, 1978-87. BMF 1990 300:1229-33.

31 Office of Population Censuses and Surveys. Birth statistics 1989. London: OPCS, 1991. (Series FMI No 18.)

32 Pharoah P, Alberman E, Doyle P, Chamberlain G Outcome of pregnancy among women in anaesthetic Outcome of pregnancy among women in anaesthetic

practice. Lancet 1977;i:34-6.
33 Wong HOC, Daling J, Cates W, Creenberg R. The epidemiology of ectopic pregnancy. Epidemiol Rev 1987; 9:70-94.

34 Office of Population Censuses and Surveys. Cancer statistics 1985. London: OPCS, 1990. (Series MBI No 18.)

35 The Ionising Radiations Regulations, 1985. London: HMSO 1985. (SI 11333.)

36 Kendle GM, Muirhead CR, Draper GJ. Parental exposure to radiation and childhood cancer. Radiological Protection to radiation and childh

37 Roman E, Doyle P. Nuclear industry family study in: abstracts from the international workshop on childhood cancer clusters and ionising radiation. Leukaemia 1994;8:2005-18.

\section{Occupational and Environmental Medicine and the electronic age}

OEM has an Email address which is 100632.3615@compuserve.com. We welcome contact by Email, including letters to the editor. Some of our reviewers already send us their reports by Email, helping to speed up the peer review process.

We are moving towards electronic publishing and for some months now we have been asking authors to send us their revised papers on disk as well as a hard copy. I am delighted to report that nearly all our authors are managing to comply with this request; far more than for other specialist journals in the BMJ Publishing group. Oddly enough, the few authors who have not sent us a disk version of their revised papers have been almost exclusively from the United Kingdom. I would be interested in suggestions for why this might be. Perhaps United Kingdom based authors read our correspondence and instructions less assiduously? Watch for revised Instructions to Authors.

The Editor 